\title{
Discrete Set Data Type IV
}

National Cancer Institute

\section{Source}

National Cancer Institute. Discrete Set Data Type IV. NCI Thesaurus. Code C160774.

A collection of identifiers from an external system that contains distinct and discrete values in no particular order. 